\title{
Frailty to predict unplanned hospitalization, stroke, bleeding and death in atrial fibrillation
}

\author{
Rebecca Gugganig $^{1,2 *}$, Stefanie Aeschbacher ${ }^{1,2 *}$, Darryl P. Leong ${ }^{3}$, Pascal Meyre ${ }^{1,2}$, Steffen \\ Blum $^{1,2}$, Michael Coslovsky ${ }^{4}$, Jürg H. Beer ${ }^{5}$, Giorgio Moschovitis ${ }^{6}$, Dominic Müller ${ }^{1}$, \\ Daniela Anker ${ }^{7}$, Nicolas Rodondi ${ }^{7,8}$, Samuel Stempfel ${ }^{1,2}$, Christian Müller $^{1,2}$, Christine \\ Meyer-Zürn ${ }^{1,2}$ Michael Kühne ${ }^{1,2}$, David Conen ${ }^{1,2,3}$, Stefan Osswald ${ }^{1,2}$, for the Swiss-AF \\ investigators
}

* Contributed equally, shared first authors

1 Cardiovascular Research Institute Basel, University Hospital Basel, University of Basel, Switzerland

2 Division of Cardiology, Department of Medicine, University Hospital Basel, University of Basel, Switzerland

3 Population Health Research Institute, McMaster University, Hamilton, Canada

4 Clinical Trial Unit Basel, Department of Clinical Research, University Hospital Basel, Switzerland

5 Department of Medicine, Cantonal Hospital of Baden and Molecular Cardiology, University Hospital of Zürich, Switzerland

6 Department of Cardiology, Ospedale Regionale di Lugano, Switzerland

7 Institute of Primary Health Care (BIHAM), University of Bern, Switzerland

8 Department of General Medicine, Inselspital, Bern University Hospital, University of Bern, Switzerland

Short title: Frailty in atrial fibrillation

Word count (text only): 3399

\section{Address for correspondence:}

Stefan Osswald MD

University Hospital Basel

Petersgraben 4

4031 Basel

Email: stefan.osswald@usb.ch

Phone: +4161265 5226

Published on behalf of the European Society of Cardiology. All rights reserved. (c) The Author(s) 2020. For permissions please email: journals.permissions@oup.com. 


\section{Abstract}

Aims: Atrial fibrillation (AF) and frailty are common, and the prevalence is expected to rise further. We aimed to investigate the prevalence of frailty and the ability of a frailty index (FI) to predict unplanned hospitalizations, stroke, bleeding and death in patients with AF.

Methods and results: Patients with known AF were enrolled in a prospective cohort study in Switzerland. Information on medical history, lifestyle-factors and clinical measurements were obtained. The primary outcome was unplanned hospitalization; secondary outcomes were allcause mortality, bleeding and stroke. The FI was measured using a cumulative deficit approach, constructed according to previously published criteria and divided into three groups (non-frail, pre-frail, frail). The association between frailty and outcomes was assessed using multivariable adjusted Cox regression models. Of the 2369 included patients, prevalence of pre-frailty and frailty was $60.7 \%$ and $10.6 \%$, respectively. Pre-frailty and frailty were associated with a higher risk of unplanned hospitalizations (adjusted hazard ratio [aHR] 1.82; 95\% confidence interval $[\mathrm{CI}], 1.49-2.22, \mathrm{p}<0.001$; and aHR 3.59; 95\%CI 2.78-4.63, $\mathrm{p}<0.001$ ), all-cause mortality (aHR 5.07; 95\%CI 2.43-10.59, p<0.001; and aHR 16.72; 95\%CI 7.7536.05, $\mathrm{p}<0.001)$, and bleeding (aHR 1.53; 95\%CI 1.11-2.13, $\mathrm{p}=0.01$; and aHR 2.46; 95\%CI 1.61-3.77, $\mathrm{p}<0.001)$. Frailty, but not pre-frailty was associated with a higher risk of stroke (aHR 3.29; 95\%CI 1.29-8.39, $\mathrm{p}=0.01)$.

Conclusion: Over two thirds of patients with AF are pre-frail or frail. These patients have a high risk for unplanned hospitalizations and other adverse events. These findings emphasize the need to carefully evaluate these patients. However, whether screening for pre-frailty and frailty and targeted prevention strategies improve outcomes needs to be shown in future studies.

Keywords: Atrial fibrillation, elderly, frailty, hospitalization, mortality

Clinical trial registration information: Clinicaltrials.gov identifier number: NCT02105844 


\section{Introduction}

Frailty is a common condition in geriatric patients, characterized by a reduced biological reserve and high vulnerability to adverse outcomes including death. ${ }^{1}$ Depending on the assessment tool and the population studied, the prevalence of frailty in patients with cardiovascular disease (CVD) was estimated from $10 \%$ to $60 \% .^{2}$

Atrial fibrillation (AF) is associated with substantial comorbidity, such as heart failure, or stroke, which by itself could contribute to frailty and disability in this patient group. ${ }^{3-5} \mathrm{AF}$ patients are treated with anticoagulants and other potent cardiovascular drugs. This may impose additional risks, such as bleeding and/or fainting,,${ }^{6,7}$ especially to frail AF patients.

The $\mathrm{CHA}_{2} \mathrm{DS}_{2}$-VASc score has been designed and validated to specifically estimate the risk of stroke for patients with AF. ${ }^{8}$ In some studies it has also proven to be predictive for mortality and bleeding in AF patients, as well as for death and major cardiovascular events in patient presenting to the emergency department with syncope. ${ }^{9-11}$ Despite the fact that AF is the most common arrhythmia with a prevalence of $13-15 \%$ in patients over 75 years ${ }^{12}$ and in older people strongly associated with frailty, ${ }^{13}$ only limited data on frailty and its association with adverse outcome events in AF patients are available.

A recent review reported a prevalence of frailty in AF patients in sixteen studies, with a range from $6 \%$ in a registry of outpatients up to $100 \%$ in a nursing home population. ${ }^{14}$ This review reported an association between frailty and mortality, but also highlighted the lack of data on frailty and its association with other adverse outcomes in AF patients in a community setting.

Therefore this study aimed to investigate the prevalence of frailty and the ability of a frailty index (FI) to predict adverse clinical outcomes in a large observational community cohort of contemporarily treated AF patients. 


\section{Methods}

\section{Study design}

The Swiss Atrial Fibrillation Cohort Study (Swiss-AF) is an ongoing prospective, observational, multicenter cohort study across 14 centers in Switzerland. Detailed information on the study design has been published previously. ${ }^{15}$ The study complies with the Declaration of Helsinki, the study protocol has been approved by the local ethics committees, and informed written consent was obtained from each participant.

\section{Study population}

Overall, 2415 patients with documented AF were enrolled between 2014 and 2017. The prespecified inclusion criteria of the cohort study were a history of previously documented AF (documented by ECG or rhythm monitoring device within the last 60 months) and age $\geq 65$ years. In order to assess the socioeconomic aspects of AF in individuals who are part of the active workforce we enrolled additionally $10 \%$ of participants aged between 45 and 65 years. Patients with exclusively short, reversible form of AF (e.g. AF following cardiac surgery) were excluded. Of the 2415 patients 46 (1.9\%) were excluded from this analysis; 30 (1.2\%) due to study termination other than death before first follow-up visit, 7 (0.3\%) due to not yet completed first follow-up and $9(0.4 \%)$ due to missing/invalid date of the primary endpoint, resulting in a total number of $2369(98.1 \%)$ patients remaining.

\section{Assessment of study variables}

Information about patient characteristics, risk-factors, comorbidities, physical activity, nutrition, current medications and medication adherence were collected by standardized case report forms and validated questionnaires. Cognitive assessment was evaluated by centrally trained study personnel using the Montreal Cognitive Assessment. ${ }^{16}$ Depressive symptoms were measured with the Geriatric Depression Scale. ${ }^{17}$ Health related quality of life was measured with the European Quality of life-5 Dimensions questionnaire (EQ-5D). ${ }^{18}$ The Barthel-Index was used to assess disability. ${ }^{19}$ 
Body height and weight were directly measured using standardized devices and BMI was calculated. Blood pressure was measured three times in a supine position after at least 5 minutes of rest using a validated device. A resting 16-lead electrocardiogram (ECG) of 5 minutes duration was acquired in every study center. Atrial fibrillation type was classified according to the guidelines of the European Society of Cardiology into paroxysmal, persistent or permanent AF. ${ }^{6}$ The degree of peripheral edema and/or rales was assessed by local investigators.

Non-fasting venous blood samples were collected from each patient at baseline. The samples were stored at $-80^{\circ} \mathrm{C}$ in a centralized biobank at the University Hospital Basel. Estimated glomerular filtration rate (eGFR) was calculated using the Chronic Kidney Disease Epidemiology Collaboration (CKD- EPI) equation..$^{20}$

\section{Follow up assessments and clinical outcome events}

Yearly follow-up examinations were performed to update and re-assess all information and measures, and to collect information about adverse outcome events. Follow-up information was collected by local study personnel at each study center. If a clinical outcome event was reported by the patient or detected in available medical records, detailed information from the corresponding hospital and/or treating physicians was collected. All-cause death, stroke and bleeding were independently adjudicated by two physicians using a standardized form. In case of disagreement, a third physician reviewed the respective outcome event.

The primary outcome for this analysis was any unplanned hospitalization. Secondary outcomes included first cardiovascular hospitalization, first non-cardiovascular hospitalization, all-cause mortality, any bleeding, defined as major and clinically relevant non- major bleeding, and all stroke, defined as ischemic or hemorrhagic stroke. Detailed definitions of outcomes are provided in Supplementary table 1. 


\section{Frailty index score}

Data of all variables included in the Frailty Index (FI) are provided in Table 1. Based on the available dataset the "deficit accumulation" approach was used. The FI was developed using 40 unweighted variables, including symptoms, signs, diseases and disabilities. ${ }^{21}$ The variables were selected according to a standard procedure to create a frailty index score as described before. ${ }^{22}$ All variables were coded according to published or self-evident cut-offs and mapped to a $0-1$ interval (indicating the occurrence and severity of a deficit). For each patient the FI score was calculated as the proportion of deficits present in relation to the number of deficits available. FI is a continuous variable scaled from 0-1 and was, similar to prior reports divided into the predefined levels non-frail $(\mathrm{FI} \leq 0.1)$, pre-frail $(\mathrm{FI}>0.1$ and $<0.25)$ and frail (FI $\geq 0.25)^{23}$

\section{Statistical analysis}

We used data up to October $1^{\text {st }}, 2018$ and included patients with at least one year of follow up. Baseline characteristics were stratified by frailty levels. Categorical variables are presented as counts (percentages) and compared using Chi-square tests. The distribution of continuous variables was analyzed using skewness, kurtosis and visual inspection of the histogram. Normally distributed continuous variables are presented as mean \pm standard deviation (SD) and compared using ANOVA. Skewed variables are presented as median (interquartile range) and compared using the Kruskal-Wallis Rank Sum-test.

Person-years of follow-up were calculated from the date of study entry to the first occurrence of an outcome event, death, date of the last visit or lost-to-follow-up, whatever occurred first. To estimate the cumulative incidence of outcomes across frailty levels we used the cumulative incidence function. To assess the association between frailty and a clinical outcome event we constructed multivariable (cause-specific) Cox regression models to calculate hazard ratios (HR) (95\% confidence intervals [95\% CI]). Multivariable models were adjusted for age, sex, type of oral anticoagulation (i.e. vitamin $\mathrm{K}$ antagonist (VKA), direct oral anticoagulants (DOAC), or no OAC), any antiplatelet therapy (i.e. Aspirin (ASS) or other 
antiplatelets), type of AF, education and smoking. For relative risk calculations the group of non-frail patients was used as reference. We estimated the population-attributable risk (PAR) proportion of frailty and pre-frailty for each outcome event, using the formula pd x (HR-1/ $\mathrm{HR}$ ), where pd is the proportion of frailty and pre-frailty among all patients with the outcome event and $\mathrm{HR}$ is the adjusted $\mathrm{HR} .{ }^{24} \mathrm{~A}$ receiver operating characteristic curve was constructed to assess the area under the curve for the age- and sex adjusted FI and the $\mathrm{CHA}_{2} \mathrm{DS}_{2}-\mathrm{VASc}$ score for the prediction of stroke within one year, and for the other outcomes. The Spearmans`s correlation coefficient was conducted for the correlation between FI and $\mathrm{CHA}_{2} \mathrm{DS}_{2}$-VASc score.

Pre-specified subgroup analyses were performed for age ( $\geq 75 y)$, sex, AF type and type of OAC. As a sensitivity analysis we recalculated the main models using Subdistribution Hazard regression as described by Fine and Gray, in order to take into account the competing risk of death. ${ }^{25} \mathrm{~A}$ p-value $<0.05$ was considered to indicate statistical significance. All statistical analyses were performed using RStudio ( $\mathrm{R}$ version 3.4.1). 


\section{Results}

\section{Baseline characteristics}

Baseline characteristics stratified by frailty level are presented in Table 2. Overall, mean $( \pm \mathrm{SD})$ age was $73( \pm 8)$ years, $647(27.3 \%)$ were female and $2141(90.4 \%)$ were treated with OAC. Among participants, $28.7 \%$ were non-frail, $60.7 \%$ were pre-frail and $10.6 \%$ were frail. Frail patients were more likely to be older, current or past smokers and to have permanent AF. The mean $\mathrm{CHA}_{2} \mathrm{DS}_{2}-\mathrm{VASc}$ score was 2.1, 3.8 and 5.4 among non-frail, pre-frail and frail patients, respectively $(\mathrm{p}<0.001)$. Compared to non-frail and pre-frail patients, frail patients were more often treated with VKA $(27.2 \%, 43.1 \%$ and $52 \%)$, but the overall frequency of OAC use did not differ across frailty levels.

\section{Outcomes}

During a median follow-up of 2.0 years, 762 of 2369 (32.2\%) patients had one or more unplanned hospitalization for any cause. Of these first unplanned hospitalizations of any cause, $281(36.9 \%)$ were cardiovascular and 481 (63.1\%) were non-cardiovascular.

Overall, $322(13.6 \%)$ patients had a first cardiovascular hospitalization and 523 $(22.1 \%)$ a first non-cardiovascular hospitalization, $50(2.1 \%)$ a stroke, $273(11.5 \%)$ a major bleeding or clinically relevant non- major bleeding and $159(6.7 \%)$ died. The cumulative incidence of any unplanned hospitalization, all-cause mortality, stroke and bleeding stratified by frailty level are shown in Figure 1.

\section{Association of frailty level and unplanned hospitalizations}

The associations between frailty levels and unplanned hospitalization are presented in Table 3. The overall incidence of any hospitalization was 19.8 per 100 patient-years, and it was 10.6, 21.5 and 45.0 per 100 patient-years in non-frail, pre-frail and frail patients, respectively. Compared to non-frail patients, the multivariable adjusted HR for hospitalization in pre-frail and frail patients were 1.82 (95\%CI 1.49-2.22) and 3.59 (95\%CI 2.78-4.63), respectively. We estimated that $42 \%$ of all unplanned hospitalizations could be attributable to pre-frailty or 
frailty.

Similar results were found for the association of pre-frailty and frailty with first cardiovascular hospitalization (adjusted HR 2.51, 95\%CI 1.77-3.55; and adjusted HR 4.96, 95\%CI 3.28-7.49) and first non-cardiovascular hospitalization (adjusted HR 1.48, 95\%CI 1.17-1.87; and adjusted HR 2.67, 95\%CI 1.97-3.62).

\section{Association of frailty level and secondary outcomes}

The overall incidence of all-cause mortality was 3.3 per 100 person-years, compared with 0.6 , 3.2 and 11.6 per 100 person-years in non-frail, pre-frail and frail patients, respectively. Prefrailty and frailty were significantly associated with all-cause mortality (adjusted HR 5.07, 95\%CI 2.43-10.59; and adjusted HR 16.72, 95\%CI 7.75-36.05). Of all deaths we estimated that $81 \%$ could be attributable to pre-frailty or frailty (Table 4).

The incidence for stroke was 1.0 per 100 person-years overall, and $0.7,1.0$ and 2.3 for non-frail, pre-frail and frail patients. For bleeding, the overall incidence was 7.0 per 100 person-years, and 3.7, 6.4 and 10.5 for non-frail, pre-frail and frail patients. Multivariable Cox regression for pre-frailty and frailty showed consistent results for bleeding (adjusted HR 1.53, 95\%CI 1.11-2.13; and adjusted HR 2.46, 95\%CI 1.61-3.77), but not for stroke (adjusted HR 1.43, 95\%CI 0.67-3.06; and adjusted HR 3.29 95\%CI 1.29-8.39). We estimated that $32 \%$ of all bleedings and $32 \%$ of all strokes could be attributable to pre-frailty or frailty (Table 4).

\section{Sensitivity and subgroup analyses}

Competing risk models for the main analyses revealed similar findings (Supplementary table 2). Subgroup analyses for the association of frailty levels with any unplanned hospitalizations and the secondary outcomes showed consistent results, and none of the interaction terms were statistically significant (Supplementary table 3). Due to the small number of outcome events, subgroup analyses for stroke were not performed. 
Receiver Operating Characteristic (ROC) curve of the age and sex adjusted FI and $\mathrm{CHA}_{2} \mathrm{DS}_{2}$-VASc score

For the prediction of stroke after one year the age and sex adjusted FI performed comparably to the $\mathrm{CHA}_{2} \mathrm{DS}_{2}$-VASc score with an AUC of 0.657 (0.557-0.745) and $0.636(0.516-0.742)$, respectively (Figure 2). For the other outcomes, for which the $\mathrm{CHA}_{2} \mathrm{DS}_{2}$-VASc score was not designed, the FI performed slightly better than the $\mathrm{CHA}_{2} \mathrm{DS}_{2}-\mathrm{VASc}$ score (Supplementary figure 1).The correlation coefficient between the FI and the $\mathrm{CHA}_{2} \mathrm{DS}_{2}-\mathrm{VASc}$ score was $0.6625, \mathrm{p}<0.001$. 


\section{Discussion}

Several findings emerged from this large community-based cohort study of AF patients. First, while the prevalence of frailty was low, almost two thirds of patients were pre-frail. Second, the majority of adverse outcomes was attributable to pre-frailty. These finding emphasize to carefully evaluate frail, and in particular pre-frail, patients. Third, the applied FI has proven to be a powerful tool to predict outcomes, with both pre-frailty and frailty being strongly associated with unplanned hospitalizations. Similar results were found for stroke, bleeding and death. Compared to the $\mathrm{CHA}_{2} \mathrm{DS}_{2}-\mathrm{VASc}$ score, the FI had a similar predictive power. Fifth, the prevalence of OAC did not differ among frailty groups, but frail patients were more likely to receive VKA. Further studies are needed to determine whether screening for frailty and targeted prevention strategies potentially reduce adverse outcomes and consecutive health related costs.

The prevalence of frailty among patients with $\mathrm{AF}$ was $10.6 \%$ and close to the lower bound of the previously reported range of $6 \%$ to $100 \%$ in a recent review. ${ }^{26}$ This may be explained by the stable condition of our patients compared to those in other studies, which included sicker and predominantly in-hospital patients, or patients from nursing homes. Another explanation could be the possible non-participation of frail patients. In addition, there are two different approaches to measure frailty ("phenotypic" vs. "deficit accumulation" frailty). ${ }^{21,27}$ Furthermore the variable components of a given FI vary between studies.

Most patients in our study were pre-frail, accounting for the highest attributable risk for all adverse outcomes. Taking a public and economic health perspective, special attention should be given to this large pre-frail patient group. Multidisciplinary programs have been shown to be an effective strategy to increase the days alive and out of hospital in AF patients. ${ }^{28}$ In addition, multicomponent exercise interventions have been shown to reverse frailty. ${ }^{29}$ Screening for frailty on a population basis is not yet recommended. ${ }^{30}$ But screening for frailty in AF patients together with a disease specific management, comprehensive geriatric assessment and care ${ }^{31}$ and multicomponent exercise interventions, would be a 
proactive approach to a population with a high percentage of pre-frailty and frailty. However, whether screening for frailty and targeted prevention strategies for pre-frail and frail AF patients improve outcomes needs to be shown in future studies.

We observed that $>40 \%$ of any unplanned hospitalizations were attributable to prefrailty and frailty (Take home figure). Nguyen and colleagues showed in a small cohort of inhospital AF patients no association between frailty and re-hospitalization. ${ }^{32}$ Further comparisons are difficult due to the lack of data addressing the association of frailty and unplanned hospitalizations in AF patients. It might appear unexpected that the rate for unplanned hospitalizations was higher for non-cardiovascular than cardiovascular reasons. Partly, this is explained by the older age and higher comorbidity burden in the frail group. Other explanations might be compromised immune response, accounting for more infections and cancer in frail patients ${ }^{33,34}$ and the higher comorbidity-rate in AF patients leading to a higher risk of non-cardiovascular disease in general. Unfortunately, we were not able to further clarify the exact reasons for hospitalizations. To identify modifiable risk factors and possibly preventable reasons for hospitalizations in pre-frail and frail AF patients further studies are needed.

We also found a strong association between frailty and stroke, bleeding and all-cause mortality, which is consistent with previous findings. ${ }^{32,35}$ The low incidence of stroke in our cohort may be explained by the high prevalence of oral anticoagulation. Nevertheless, after multivariable adjustment (including type of OAC) frailty remained an independent predictor of stroke. Compared to the $\mathrm{CHA}_{2} \mathrm{DS}_{2}$-VASc score, the FI had a similar predictive power in this study of AF patients for the prediction of unplanned hospitalization, stroke, bleeding and death, with a strong correlation. When interpreting these results one should note that a simple clinical risk score such as the $\mathrm{CHA}_{2} \mathrm{DS}_{2}$-VASc score not validated for frailty performs comparably to our 40-item frailty score.

While the $\mathrm{CHA}_{2} \mathrm{DS}_{2}$-VASc score was highest in frail patients, the prevalence of OAC did not differ among frailty groups, with a high overall prevalence of $90.4 \%$. This high 
prevalence is in line with other studies assessing the prescription of OAC in AF patients in Europe at the time of our study. ${ }^{36}$ Although DOACs with their better risk/benefit ratio seem preferable in frail patients, ${ }^{37}$ in our study frail patients were more likely to receive VKA. This finding may partly be explained by a physician preference for close INR monitoring, especially in elderly or frail AF patients. ${ }^{38}$ A study from the U.S. found, that DOACs were less likely prescribed to elderly patients with an increased risk for stroke and bleeding, and to those with more comorbidities. ${ }^{39}$ However, the higher rate of renal dysfunction in frail patients cannot explain this observation alone. Another explanation may be the time period of patient enrollment to our study (2014-2017), since the first DOAC in Switzerland for prevention of stroke in AF was approved 2012. A study in Swiss AF patients found an increase of DOAC use between 2010 and 2015, but most patients stayed on their initial therapy with VKA. ${ }^{40}$ As expected the bleeding risk seemed to be higher on OAC in all frailty groups. But there were no significant differences in bleeding risk with regard to the type of OAC, may be due to the small number of events in the subgroups. To clarify the question about OAC in frail AF patients, more clinical trials in this particular population are needed.

Our study has the advantage of being a large community-based cohort of wellcharacterized patients with a very low rate of missing values, which enabled us to build a strong FI. Also, the clinical outcomes were collected accurately and validated by independent experts. However, some potential limitations need to be considered. First, being an observational study, we cannot confirm causality, and residual confounding may persist despite comprehensive multivariable adjustment. Second, we used only a single measurement of frailty at study entry, which is associated with some risk of misclassification. Nevertheless, our results and those of others have shown, that a FI based on random composites of deficits is a robust model and capable to appropriately predict outcomes. ${ }^{41}$ Third, study patients were mostly $>65$ years old, which limits the generalizability of these findings. 


\section{Conclusions}

In this large cohort of elderly AF patients, the FI was a powerful tool to predict unplanned hospitalizations and other adverse outcomes. The risk of unplanned hospitalization was highest among frail patients, but pre-frail patients accounted for the largest proportion of total number of hospitalizations, a finding that emphasizes the clinical need to carefully evaluate these patients. To determine whether screening and specific interventions for pre-frail and frail AF patients can potentially reduce adverse outcomes and its socio-economic consequences further studies are needed. 


\section{Funding}

This work was supported by grants of the Swiss National Science Foundation (grant numbers 33CS30_1148474 and 33CS30_177520), the Foundation for Cardiovascular Research Basel and the University of Basel.

\section{Conflict of interest}

R.G. has nothing to disclose. S.A. has nothing to disclose. D.P.L. has nothing to disclose. P.M. has nothing to disclose. S.B. has nothing to disclose. M.C. has nothing to disclose. J.H.B. reports grants from Bayer, grants from Swiss National Foundation of Science, grants from The Swiss Heart Foundation, personal fees from Daiichi-Sankyo, grants from Pfizer, personal fees from Sanofi Aventis, outside the submitted work. G.M. reports personal fees from Boehringer Ingelheim, outside the submitted work. D.M. has nothing to disclose. D.A. has nothing to disclose. N.R. has nothing to disclose. S.S. has nothing to disclose. C.M. reports grants from Swiss National Science Foundation, grants from Swiss Heart Foundation, grants from European Union, grants from Cardiovascular Research Foundation Basel, grants from KTI, grants from University of Basel, grants from Abbott, grants from Beckman Coulter, grants from Biomerieux, grants from BRAHMS, grants from Ortho Clinical Diagnostics, grants from Quidel, grants from Roche, grants from Siemens, grants from Singulex, grants from Sphingotec, personal fees from Astra Zeneca, personal fees from Amgen, personal fees from BMS, personal fees from Boehringer Ingelheim, personal fees from BRAHMS, personal fees from Idorsia, personal fees from Novartis, personal fees from Roche, personal fees from Sanofi, personal fees from Siemens, personal fees from Singulex, outside the submitted work. C.M-Z reports personal fees from Vifor Pharma, personal fees from Novartis, grants from Medtronic, outside the submitted work. M.K. reports personal fees from Bayer, personal fees from Boehringer Ingelheim, personal fees from DaiichiSankyo, personal fees from Pfizer, personal fees from Bristol-Myers Squibb, outside the 
submitted work. D.C. reports personal fees from Servier, outside the submitted work. S.O. has nothing to disclose. The other authors declare no competing interests. 


\section{References}

1. Rockwood K, Howlett SE, Macknight C, Beattie BL, Bergman H, Hebert R, Hogan DB, Wolfson C, McDowell I. Prevalence, attributes, and outcomes of fitness and frailty in community-dwelling older adults: report from the Canadian study of health and aging. J Gerontol A Biol Sci Med Sci 2004;59(12):1310-7.

2. Afilalo J, Karunananthan S, Eisenberg MJ, Alexander KP, Bergman H. Role of frailty in patients with cardiovascular disease. Am J Cardiol 2009;103(11):1616-21. 3. Pistoia F, Sacco S, Tiseo C, Degan D, Ornello R, Carolei A. The Epidemiology of Atrial Fibrillation and Stroke. Cardiol Clin 2016;34(2):255-68.

4. Pellicori P, Urbinati A, Kaur K, Zhang J, Shah P, Kazmi S, Capucci A, Cleland JGF, Clark AL. Prevalence and Incidence of Atrial Fibrillation in Ambulatory Patients With Heart Failure. Am J Cardiol 2019.

5. Walker DM, Gale CP, Lip G, Martin-Sanchez FJ, Mclntyre HF, Mueller C, Price S, Sanchis J, Vidan MT, Wilkinson C, Zeymer U, Bueno H. Editor's Choice - Frailty and the management of patients with acute cardiovascular disease: A position paper from the Acute Cardiovascular Care Association. Eur Heart J Acute Cardiovasc Care 2018;7(2):176-193.

6. Camm AJ, Kirchhof P, Lip GY, Schotten U, Savelieva I, Ernst S, Van Gelder IC, AlAttar N, Hindricks G, Prendergast B, Heidbuchel H, Alfieri O, Angelini A, Atar D, Colonna P, De Caterina R, De Sutter J, Goette A, Gorenek B, Heldal M, Hohloser SH, Kolh P, Le Heuzey JY, Ponikowski P, Rutten FH. Guidelines for the management of atrial fibrillation: the Task Force for the Management of Atrial Fibrillation of the European Society of Cardiology (ESC). Europace 2010;12(10):1360-420.

7. Kirchhof P, Benussi S, Kotecha D, Ahlsson A, Atar D, Casadei B, Castella M, Diener HC, Heidbuchel H, Hendriks J, Hindricks G, Manolis AS, Oldgren J, Popescu BA, Schotten U, Van Putte B, Vardas P. 2016 ESC Guidelines for the management of atrial fibrillation developed in collaboration with EACTS. Eur Heart J 2016;37(38):2893-2962.

8. Lip GY, Nieuwlaat R, Pisters R, Lane DA, Crijns HJ. Refining clinical risk stratification for predicting stroke and thromboembolism in atrial fibrillation using a novel risk factor-based approach: the euro heart survey on atrial fibrillation. Chest 2010;137(2):263-72.

9. Apiyasawat S, Tangcharoen T, Wisaratapong T, Yamwong S, Wiboonpolprasert S, Sritara P. CHA(2)DS(2)-VASc scores predict mortality after hospitalization for atrial fibrillation. Int J Cardiol 2015;185:293-6.

10. Lee KT, Chang SH, Yeh YH, Tu HT, Chan YH, Kuo CT, See LC. The CHA(2)DS(2)VASc Score Predicts Major Bleeding in Non-Valvular Atrial Fibrillation Patients Who Take Oral Anticoagulants. J Clin Med 2018;7(10).

11. du Fay de Lavallaz J, Badertscher P, Nestelberger T, Isenrich R, Miro O, Salgado E, Geigy N, Christ M, Cullen L, Than M, Martin-Sanchez FJ, Bustamante Mandrion J, Di Somma S, Peacock WF, Kawecki D, Boeddinghaus J, Twerenbold R, Puelacher C, Wussler D, Strebel I, Keller DI, Poepping I, Kuhne M, Mueller C, Reichlin T, Gimenez MR, Walter J, Kozhuharov N, Shrestha S, Mueller D, Sazgary L, Morawiec B, Muzyk P, Nowalany-Kozielska E, Freese M, Stelzig C, Meissner K, Kulangara C, Hartmann B, Ferel I, Sabti Z, Greenslade J, Hawkins T, Rentsch K, von Eckardstein A, Buser A, Kloos W, 
Lohrmann J, Osswald S. Prospective validation of prognostic and diagnostic syncope scores in the emergency department. Int J Cardiol 2018;269:114-121.

12. Go AS, Hylek EM, Phillips KA, Chang Y, Henault LE, Selby JV, Singer DE.

Prevalence of diagnosed atrial fibrillation in adults: national implications for rhythm management and stroke prevention: the AnTicoagulation and Risk Factors in Atrial Fibrillation (ATRIA) Study. JAMA 2001;285(18):2370-5.

13. Polidoro A, Stefanelli F, Ciacciarelli M, Pacelli A, Di Sanzo D, Alessandri C. Frailty in patients affected by atrial fibrillation. Arch Gerontol Geriatr 2013;57(3):325-7.

14. Wilkinson C, Todd O, Clegg A, Gale CP, Hall M. Management of atrial fibrillation for older people with frailty: a systematic review and meta-analysis. Age Ageing 2018.

15. Conen D, Rodondi N, Mueller A, Beer J, Auricchio A, Ammann P, Hayoz D, Kobza R, Moschovitis G, Shah D, Schlaepfer J, Novak J, di Valentino M, Erne P, Sticherling C, Bonati L, Ehret G, Roten L, Fischer U, Monsch A, Stippich C, Wuerfel J, Schwenkglenks M, Kuehne M, Osswald S. Design of the Swiss Atrial Fibrillation Cohort Study (SwissAF): structural brain damage and cognitive decline among patients with atrial fibrillation. Swiss Med Wkly 2017;147:w14467.

16. Nasreddine ZS, Phillips NA, Bedirian V, Charbonneau S, Whitehead V, Collin I, Cummings JL, Chertkow H. The Montreal Cognitive Assessment, MoCA: a brief screening tool for mild cognitive impairment. J Am Geriatr Soc 2005;53(4):695-9.

17. Sheikh JI, Yesavage JA, Brooks JO, 3rd, Friedman L, Gratzinger P, Hill RD, Zadeik A, Crook T. Proposed factor structure of the Geriatric Depression Scale. Int Psychogeriatr 1991;3(1):23-8.

18. Rasanen P, Roine E, Sintonen $H$, Semberg-Konttinen $V$, Ryynanen OP, Roine R. Use of quality-adjusted life years for the estimation of effectiveness of health care: $A$ systematic literature review. Int J Technol Assess Health Care 2006;22(2):235-41.

19. Mahoney FI, Barthel DW. FUNCTIONAL EVALUATION: THE BARTHEL INDEX. Md State Med J 1965;14:61-5.

20. Inker LA, Schmid CH, Tighiouart H, Eckfeldt JH, Feldman HI, Greene T, Kusek JW, Manzi J, Van Lente F, Zhang YL, Coresh J, Levey AS. Estimating glomerular filtration rate from serum creatinine and cystatin C. N Engl J Med 2012;367(1):20-9.

21. Rockwood K, Mitnitski A. Frailty in relation to the accumulation of deficits. J Gerontol A Biol Sci Med Sci 2007;62(7):722-7.

22. Searle SD, Mitnitski A, Gahbauer EA, Gill TM, Rockwood K. A standard procedure for creating a frailty index. BMC Geriatr 2008;8:24.

23. Song X, Mitnitski A, Rockwood K. Prevalence and 10-year outcomes of frailty in older adults in relation to deficit accumulation. J Am Geriatr Soc 2010;58(4):681-7.

24. Rockhill B, Newman B, Weinberg C. Use and misuse of population attributable fractions. Am J Public Health 1998;88(1):15-9.

25. Berger M, Schmid M, Welchowski T, Schmitz-Valckenberg S, Beyersmann J.

Subdistribution hazard models for competing risks in discrete time. Biostatistics 2018. 26. Villani ER, Tummolo AM, Palmer K, Gravina EM, Vetrano DL, Bernabei R, Onder G, Acampora N. Special issue frailty - frailty and atrial fibrillation: A systematic review. Eur J Intern Med 2018.

27. Fried LP, Tangen CM, Walston J, Newman AB, Hirsch C, Gottdiener J, Seeman T, Tracy R, Kop WJ, Burke G, McBurnie MA. Frailty in older adults: evidence for a phenotype. J Gerontol A Biol Sci Med Sci 2001;56(3):M146-56. 
28. Stewart S, Ball J, Horowitz JD, Marwick TH, Mahadevan G, Wong C, Abhayaratna WP, Chan YK, Esterman A, Thompson DR, Scuffham PA, Carrington MJ. Standard versus atrial fibrillation-specific management strategy (SAFETY) to reduce recurrent admission and prolong survival: pragmatic, multicentre, randomised controlled trial. Lancet 2015;385(9970):775-84.

29. Tarazona-Santabalbina FJ, Gomez-Cabrera MC, Perez-Ros P, Martinez-Arnau FM, Cabo H, Tsaparas K, Salvador-Pascual A, Rodriguez-Manas L, Vina J. A Multicomponent Exercise Intervention that Reverses Frailty and Improves Cognition, Emotion, and Social Networking in the Community-Dwelling Frail Elderly: A Randomized Clinical Trial. J Am Med Dir Assoc 2016;17(5):426-33.

30. Turner $G$, Clegg A. Best practice guidelines for the management of frailty: a British Geriatrics Society, Age UK and Royal College of General Practitioners report. Age Ageing 2014;43(6):744-7.

31. Pilotto A, Cella A, Pilotto A, Daragjati J, Veronese N, Musacchio C, Mello AM, Logroscino G, Padovani A, Prete C, Panza F. Three Decades of Comprehensive Geriatric Assessment: Evidence Coming From Different Healthcare Settings and Specific Clinical Conditions. J Am Med Dir Assoc 2017;18(2):192 e1-192 e11.

32. Nguyen TN, Cumming RG, Hilmer SN. The Impact of Frailty on Mortality, Length of Stay and Re-hospitalisation in Older Patients with Atrial Fibrillation. Heart Lung Circ 2016;25(6):551-7.

33. Conen D, Wong JA, Sandhu RK, Cook NR, Lee IM, Buring JE, Albert CM. Risk of Malignant Cancer Among Women With New-Onset Atrial Fibrillation. JAMA Cardiol 2016;1(4):389-96.

34. Collerton J, Martin-Ruiz C, Davies K, Hilkens CM, Isaacs J, Kolenda C, Parker C, Dunn M, Catt M, Jagger C, von Zglinicki T, Kirkwood TB. Frailty and the role of inflammation, immunosenescence and cellular ageing in the very old: cross-sectional findings from the Newcastle 85+ Study. Mech Ageing Dev 2012;133(6):456-66.

35. Perera V, Bajorek BV, Matthews S, Hilmer SN. The impact of frailty on the utilisation of antithrombotic therapy in older patients with atrial fibrillation. Age Ageing 2009;38(2):156-62.

36. Mazurek M, Huisman MV, Rothman KJ, Paquette M, Teutsch C, Diener HC, Dubner SJ, Halperin JL, Ma CS, Zint K, Elsaesser A, Lu S, Lip GYH. Regional Differences in Antithrombotic Treatment for Atrial Fibrillation: Insights from the GLORIA-AF Phase II Registry. Thromb Haemost 2017;117(12):2376-2388.

37. Patti G, Mantione L, Bressi E, Bisignani A. Efficacy and safety of oral anticoagulant therapy in frail patients with atrial fibrillation. Monaldi Arch Chest Dis 2018;88(2):958.

38. Camm AJ, Pinto FJ, Hankey GJ, Andreotti F, Hobbs FD. Non-vitamin K antagonist oral anticoagulants and atrial fibrillation guidelines in practice: barriers to and strategies for optimal implementation. Europace 2015;17(7):1007-17.

39. Zhu J, Alexander GC, Nazarian S, Segal JB, Wu AW. Trends and Variation in Oral Anticoagulant Choice in Patients with Atrial Fibrillation, 2010-2017. Pharmacotherapy 2018;38(9):907-920.

40. Zimny M, Blum S, Ammann P, Erne P, Moschovitis G, Di Valentino M, Shah D, Schläpfer J, Vogt C, Tabord A, Kuehne M, Sticherling C, Osswald S, Conen D. Uptake of 
non-vitamin $\mathrm{K}$ antagonist oral anticoagulants in patients with atrial fibrillation - a prospective cohort study. Swiss Med Wkly 2017;147:w14410.

41. Rockwood K, Mitnitski A, Song X, Steen B, Skoog I. Long-term risks of death and institutionalization of elderly people in relation to deficit accumulation at age 70. J Am Geriatr Soc 2006;54(6):975-9. 
Figure legends

Figure 1. Cumulative incidence of clinical outcomes stratified by levels of frailty

Cumulative incidence of unplanned hospitalization s (a), all- cause mortality (b), bleeding (c) and stroke (d) stratified by frailty level.

Figure 2. Receiver Operating Characteristic (ROC) curve of the adjusted FI and $\mathrm{CHA}_{2} \mathrm{DS}_{2}-\mathrm{VASc}$ score for stroke

Take home figure. Prevalence and impact of frailty in patients with AF 
Table 1. Variables of the Frailty Index Score stratified by level of frailty

\begin{tabular}{|c|c|c|c|c|}
\hline \multirow[b]{3}{*}{$\mathrm{n}$} & \multirow{3}{*}{$\begin{array}{l}\text { Overall } \\
2369(100)\end{array}$} & \multicolumn{3}{|c|}{ Stratified by frailty level } \\
\hline & & non-frail & pre-frail & frail \\
\hline & & $681(28.7)$ & $1436(60.7)$ & $252(10.6)$ \\
\hline Physical activity (Yes/No) & $1095(46.3)$ & $495(72.9)$ & $562(39.2)$ & $38(15.1)$ \\
\hline History of myocardial infarction & $385(16.3)$ & $22(3.2)$ & $267(18.6)$ & $96(38.1)$ \\
\hline History of PTCA/ Stent & $561(23.7)$ & $45(6.6)$ & $397(27.6)$ & $119(47.2)$ \\
\hline History of Stroke / TIA & $473(20.0)$ & $67(9.8)$ & $312(21.8)$ & $94(37.3)$ \\
\hline History of systemic embolism & $125(5.3)$ & $11(1.6)$ & $84(5.9)$ & $30(11.9)$ \\
\hline History of congestive heart failure & $613(25.9)$ & $38(5.6)$ & $413(28.8)$ & $162(64.3)$ \\
\hline History of hypertension & $1642(69.3)$ & $288(42.3)$ & $1123(78.2)$ & $231(91.7)$ \\
\hline History of diabetes mellitus & $403(17.0)$ & $10(1.5)$ & $268(18.7)$ & $125(49.6)$ \\
\hline History of peripheral vasclular disease & $190(8.0)$ & $7(1.0)$ & $112(7.8)$ & $71(28.2)$ \\
\hline History of chronic kidney disease & $498(21.0)$ & $16(2.4)$ & $336(23.4)$ & $146(57.9)$ \\
\hline History of thyroid disease & $343(14.5)$ & $50(7.3)$ & $224(15.6)$ & $69(27.4)$ \\
\hline History of malignacy & $378(16.0)$ & $55(8.1)$ & $247(17.2)$ & $76(30.2)$ \\
\hline History of major bleeding & $149(6.3)$ & $12(1.8)$ & $92(6.4)$ & $45(17.9)$ \\
\hline History of minor bleeding & $253(10.7)$ & $23(3.4)$ & $168(11.7)$ & $62(24.6)$ \\
\hline History of gastric ulcera & $106(4.5)$ & $9(1.3)$ & $57(4.0)$ & $40(15.9)$ \\
\hline Recurrent falls & $198(8.4)$ & $9(1.3)$ & $115(8.0)$ & $74(29.4)$ \\
\hline Other medical problems & $639(27.0)$ & $107(15.7)$ & $422(29.4)$ & $110(43.7)$ \\
\hline Edema & $494(20.9)$ & $34(5.0)$ & $341(23.8)$ & $119(47.2)$ \\
\hline Rales & $75(3.2)$ & $3(0.4)$ & $43(3.0)$ & $29(11.5)$ \\
\hline Body mass index & $28.0 \pm 4.8$ & $26.5 \pm 3.8$ & $28.0 \pm 4.9$ & $29.0 \pm 5.5$ \\
\hline Systolic blood pressure & $134 \pm 18.7$ & $131 \pm 15.4$ & $135 \pm 19.4$ & $134 \pm 22.0$ \\
\hline \multicolumn{5}{|l|}{ Doing usual activity (EQ- 5D) } \\
\hline unable & $20(0.8)$ & $0(0.0)$ & $8(0.6)$ & $12(4.8)$ \\
\hline some problems & $324(13.7)$ & $13(1.9)$ & $192(13.4)$ & $119(47.2)$ \\
\hline no problems & $2024(85.4)$ & $667(97.9)$ & $1236(86.1)$ & $121(48.0)$ \\
\hline \multicolumn{5}{|c|}{ Having pain or other physical issues (EQ- 5D) } \\
\hline a lot of pain & $60(2.5)$ & $1(0.1)$ & $35(2.4)$ & $24(9.5)$ \\
\hline some pain & $1023(43.2)$ & $176(25.8)$ & $679(47.3)$ & $168(66.7)$ \\
\hline no pain & $1283(54.2)$ & $503(73.9)$ & $721(50.2)$ & $59(23.4)$ \\
\hline \multicolumn{5}{|l|}{ Feeling worried, sad or unhappy (EQ- 5D) } \\
\hline very & $15(0.6)$ & $2(0.3)$ & $8(0.6)$ & $5(2.0)$ \\
\hline a bit & $453(19.1)$ & $80(11.7)$ & $285(19.8)$ & $88(34.9)$ \\
\hline not & $1900(80.2)$ & $598(87.8)$ & $1143(79.6)$ & $159(63.1)$ \\
\hline Self-rated health & $72 \pm 17.5$ & $82 \pm 11.6$ & $71 \pm 16.9$ & $56 \pm 18.8$ \\
\hline \multicolumn{5}{|l|}{ Orienation (Part of MoCA) } \\
\hline 0 & $1(0.0)$ & $0(0.0)$ & $1(0.1)$ & $0(0.0)$ \\
\hline 1 & $0(0.0)$ & $0(0.0)$ & $0(0.0)$ & $0(0.0)$ \\
\hline 2 & $3(0.1)$ & $0(0.0)$ & $0(0.0)$ & $3(1.2)$ \\
\hline 3 & $4(0.2)$ & $1(0.1)$ & $3(0.2)$ & $0(0.0)$ \\
\hline 4 & $17(0.7)$ & $2(0.3)$ & $10(0.7)$ & $5(2.0)$ \\
\hline 5 & $144(6.1)$ & $25(3.7)$ & $90(6.3)$ & $29(11.5)$ \\
\hline 6 & $2198(92.8)$ & $652(95.7)$ & $1331(92.8)$ & $215(85.3)$ \\
\hline \multicolumn{5}{|c|}{ Mathematical performance (Part of MoCA) } \\
\hline 0 & $19(0.8)$ & $1(0.1)$ & $12(0.8)$ & $6(2.4)$ \\
\hline 1 & $44(1.9)$ & $7(1.0)$ & $29(2.0)$ & $8(3.2)$ \\
\hline 2 & $175(7.4)$ & $32(4.7)$ & $109(7.6)$ & $34(13.5)$ \\
\hline 3 & 2127 (89.8) & $639(93.8)$ & $1285(89.5)$ & $203(80.6)$ \\
\hline
\end{tabular}




\begin{tabular}{|c|c|c|c|c|}
\hline 0 & $304(12.8)$ & $39(5.7)$ & $204(14.2)$ & $61(24.2)$ \\
\hline 1 & $184(7.8)$ & $30(4.4)$ & $130(9.1)$ & $24(9.5)$ \\
\hline 2 & $372(15.7)$ & $82(12.0)$ & $237(16.5)$ & $53(21.0)$ \\
\hline 3 & $501(21.2)$ & $137(20.1)$ & $317(22.1)$ & $47(18.7)$ \\
\hline 4 & $541(22.8)$ & $188(27.6)$ & $316(22.0)$ & $37(14.7)$ \\
\hline 5 & $463(19.6)$ & $202(29.7)$ & $231(16.1)$ & $30(11.9)$ \\
\hline Verbal fluency (Part of MoCA) & $10 \pm 4.0$ & $12 \pm 4.0$ & $9 \pm 3.8$ & $8 \pm 3.2$ \\
\hline Depression (GDS) & $1(1.9)$ & $1(1.4)$ & $2(1.9)$ & $3(2.6)$ \\
\hline \multicolumn{5}{|l|}{ Feeding (Barthel- Index) } \\
\hline unable & $0(0.0)$ & $0(0.0)$ & $0(0.0)$ & $0(0.0)$ \\
\hline needs help & $8(0.3)$ & $0(0.0)$ & $3(0.2)$ & $5(2.0)$ \\
\hline Independent & $2359(99.7)$ & $679(100)$ & $1433(99.8)$ & $247(98.0)$ \\
\hline \multicolumn{5}{|l|}{ Personal grooming (Barthel- Index) } \\
\hline needs help & $12(0.5)$ & $1(0.1)$ & $1(0.1)$ & $10(4.0)$ \\
\hline independent & $2357(99.5)$ & $680(100.0)$ & $1435(99.9)$ & $242(96.0)$ \\
\hline \multicolumn{5}{|l|}{ Bathing (Barthel- Index) } \\
\hline needs help & $48(2.0)$ & 0 & $8(0.6)$ & $40(15.9)$ \\
\hline independent & $2321(98.0)$ & $681(100.0)$ & $1428(99.4)$ & $212(84.1)$ \\
\hline \multicolumn{5}{|l|}{ Dressing (Barthel- Index) } \\
\hline dependent & $1(0.0)$ & $0(0.0)$ & $0(0.0)$ & $1(0.4)$ \\
\hline needs help & $33(1.4)$ & $0(0.0)$ & $6(0.4)$ & $27(10.7)$ \\
\hline independent & $2335(98.6)$ & $681(100.0)$ & $1430(99.6)$ & $224(88.9)$ \\
\hline \multicolumn{5}{|l|}{ Toilet use (Barthel- Index) } \\
\hline dependent & $0(0.0)$ & $0(0.0)$ & $0(0.0)$ & $0(0.0)$ \\
\hline needs help & $12(0.5)$ & $0(0.0)$ & $5(0.3)$ & $7(2.8)$ \\
\hline independent & $2357(99.5)$ & $681(100.0)$ & $1431(99.7)$ & $245(97.2)$ \\
\hline \multicolumn{5}{|l|}{ Urinary continence (Barthel- Index) } \\
\hline incontinent & $29(1.2)$ & $0(0.0)$ & $15(1.0)$ & $14(5.6)$ \\
\hline occasional accident & $183(7.7)$ & $21(3.1)$ & $121(8.4)$ & $41(16.3)$ \\
\hline continent & $2157(91.1)$ & $660(96.9)$ & $1300(90.5)$ & $197(78.2)$ \\
\hline \multicolumn{5}{|l|}{ Bowel continence (Barthel- Index) } \\
\hline incontinent & $7(0.3)$ & $0(0.0)$ & $3(0.2)$ & $4(1.6)$ \\
\hline occasional accident & $51(2.2)$ & $1(0.1)$ & $36(2.5)$ & $14(5.6)$ \\
\hline continent & $2311(97.6)$ & $680(99.9)$ & $1397(97.3)$ & $234(92.9)$ \\
\hline \multicolumn{5}{|l|}{ Transfer (Barthel- Index) } \\
\hline unable & $0(0.0)$ & $0(0.0)$ & $0(0.0)$ & $0(0.0)$ \\
\hline major help & $3(0.1)$ & $0(0.0)$ & $2(0.1)$ & $1(0.4)$ \\
\hline minor help & $31(1.3)$ & $0(0.0)$ & $11(0.8)$ & $20(7.9)$ \\
\hline independent & $2334(98.6)$ & $680(100.0)$ & $1423(99.1)$ & $231(91.7)$ \\
\hline \multicolumn{5}{|l|}{ Mobility (Barthel- Index) } \\
\hline immobile & $1(0.0)$ & $0(0.0)$ & $1(0.1)$ & $0(0.0)$ \\
\hline wheelchair independent & $7(0.3)$ & $0(0.0)$ & $1(0.1)$ & $6(2.4)$ \\
\hline walks with help of one person & $68(2.9)$ & $0(0.0)$ & $23(1.6)$ & $45(17.9)$ \\
\hline independent (but may use any aid) & $2293(96.8)$ & $681(100.0)$ & $1411(98.3)$ & $201(79.8)$ \\
\hline \multicolumn{5}{|l|}{ Stairs (Barthel- Index) } \\
\hline unable & $17(0.7)$ & $1(0.1)$ & $3(0.2)$ & $13(5.2)$ \\
\hline needs help & $61(2.6)$ & $0(0.0)$ & $26(1.8)$ & $35(13.9)$ \\
\hline independent & $2291(96.7)$ & $680(99.9)$ & $1407(98.0)$ & $204(81.0)$ \\
\hline
\end{tabular}

Data are presented as mean \pm standard deviation, or median (interquartile range), or number (percentage)

Levels of frailty: frail (frailty index $\geq 0.25$ ), pre- frail (frailty index $<0.25$ and $>0.1$ ), non- frail (frailty index $\leq 0.1$ )

Missing values: Physical activity $n=3$, History of Stroke/TIA $n=2$, History of congestive heart failure $n=2$, History of chronic kidney disease $n=2$, History of minor bleeding $n=2$, Edema $n=3$, Rales $n=3$, Systolic blood pressure $n=16$, Diastolic blood pressure $n=16$, Verbal fluency $n=3$, Depression $n=4$ 
Table 2. Baseline characteristics (not part of the Frailty Index Score) stratified by frailty level

\begin{tabular}{|c|c|c|c|c|c|}
\hline \multirow[b]{3}{*}{$\mathrm{n}(\%)$} & \multirow[b]{2}{*}{ Overall } & \multicolumn{3}{|c|}{ Stratified by frailty level } & \multirow{3}{*}{ p-value } \\
\hline & & non-frail & pre-frail & frail & \\
\hline & $2369(100)$ & $681(28.7)$ & $1436(60.7)$ & $252(10.6)$ & \\
\hline Age, years & $73 \pm 8$ & $69 \pm 8$ & $75 \pm 8$ & $77 \pm 7$ & $<0.001$ \\
\hline Female Sex & $647(27.3)$ & $163(23.9)$ & $412(28.7)$ & $72(28.6)$ & 0.06 \\
\hline Smoking & & & & & $<0.001$ \\
\hline Current & $172(7.3)$ & $41(6.0)$ & $104(7.2)$ & $27(10.7)$ & \\
\hline Past & $1157(48.8)$ & $301(44.2)$ & 717 (49.9) & $139(55.2)$ & \\
\hline Never & $1040(43.9)$ & $339(49.8)$ & $615(42.8)$ & $86(34.1)$ & \\
\hline $\mathrm{CHA}_{2} \mathrm{DS}_{2}$-VASc Score & $3.5 \pm 1.7$ & $2.1 \pm 1.3$ & $3.8 \pm 1.4$ & $5.4 \pm 1.3$ & $<0.001$ \\
\hline Atrial fibrillation- Type & & & & & $<0.001$ \\
\hline Paroxysmal & $1062(44.8)$ & $357(52.4)$ & $608(42.3)$ & $97(38.5)$ & \\
\hline Persistent & $694(29.3)$ & $217(31.9)$ & $421(29.3)$ & $56(22.2)$ & \\
\hline Permanent & $613(25.9)$ & $107(15.7)$ & $407(28.3)$ & $99(39.3)$ & \\
\hline Type of oral anticoagulation & & & & & $<0.001$ \\
\hline VKA & $936(39.5)$ & $186(27.2)$ & $619(43.1)$ & $131(52.0)$ & \\
\hline DOAC & 1205 (50.9) & $416(61.1)$ & $698(48.6)$ & $91(36.1)$ & \\
\hline
\end{tabular}




\section{No OAC}

Aspirin

Other antiplatelet therapy

Dual antiplatelet therapy

eGFR $<30 \mathrm{ml} / \mathrm{min} / 1.73 \mathrm{~m} 2$ (CKD- EPI)
$30(11.9)$

$399(16.8)$

$52(7.6)$

$278(19.4)$

$69(27.4)$

$<0.001$

$147(6.2)$

$16(2.4)$

$109(7.6)$

$22(8.7)$

$<0.001$
$8(1.2)$

$3(0.4)$

$54(3.8)$

$14(5.6)$

0.001

$144(6.2)$

$98(7.0)$

$43(17.6)$

$<0.001$

Data are presented as mean \pm standard deviation , or numbers (percentage); estimated glomerular filtration rate (eGFR)

Levels of frailty: frail (frailty index $\geq 0.25$ ), pre- frail (frailty index $<0.25$ and $>0.1$ ), non- frail (frailty index $\leq 0.1$ )

Missing values: Smoking $n=3, \mathrm{CHA}_{2} \mathrm{DS}_{2}$-VASc Score $\mathrm{n}=3$, other antiplatelet therapy $\mathrm{n}=5$, eGFR $\mathrm{n}=53$ 
Table 3. Cox Regression for the Association between frailty and unplanned hospitalizations

\begin{tabular}{|c|c|c|c|c|c|c|c|c|}
\hline Level of frailty & $\begin{array}{l}\text { Events/no.at } \\
\text { risk }\end{array}$ & Person-years & $\begin{array}{l}\text { Incidence rate } \\
\text { per } 100 \text { person- } \\
\text { years }\end{array}$ & $\begin{array}{l}\text { Population } \\
\text { attributable } \\
\text { risk }\end{array}$ & $\begin{array}{l}\text { HR }(95 \% \text { CI }) \\
\text { unadjusted }\end{array}$ & p-value & $\begin{array}{l}\mathrm{HR}(95 \% \mathrm{CI}) \\
\text { adjusted }\end{array}$ & p-value \\
\hline & \multicolumn{8}{|c|}{ Any unplanned hospitalization } \\
\hline non- frail & 135 / 681 & 1273 & 10.6 & & Ref. & & Ref. & \\
\hline pre- frail & $488 / 1436$ & 2267 & 21.5 & 0.29 & $2.00(1.65-2.42)$ & $<0.001$ & $1.82(1.49-2.22)$ & $<0.001$ \\
\hline \multirow[t]{2}{*}{ frail } & $139 / 252$ & 309 & 45.0 & 0.13 & $4.10(3.23-5.19)$ & $<0.001$ & $3.59(2.78-4.63)$ & $<0.001$ \\
\hline & \multicolumn{8}{|c|}{ First cardiovascular hospitalization } \\
\hline non- frail & $41 / 681$ & 1393 & 3.0 & & Ref. & & Ref. & \\
\hline pre- frail & $213 / 1436$ & 2630 & 8.1 & 0.40 & $2.70(1.93-3.77)$ & $<0.001$ & $2.51(1.77-3.55)$ & $<0.001$ \\
\hline \multirow[t]{2}{*}{ frail } & $68 / 252$ & 409 & 16.6 & 0.17 & $5.44(3.69-8.02)$ & $<0.001$ & $4.96(3.28-7.49)$ & $<0.001$ \\
\hline & \multicolumn{8}{|c|}{ First non-cardiovascular hospitalization } \\
\hline non- frail & 103 / 681 & 1333 & 7.7 & & Ref. & & Ref. & \\
\hline pre- frail & $329 / 1436$ & 2512 & 13.1 & 0.20 & $1.70(1.36-2.12)$ & $<0.001$ & $1.48(1.17-1.87)$ & 0.001 \\
\hline frail & $91 / 252$ & 363 & 25.1 & 0.11 & $3.24(2.45-4.30)$ & $<0.001$ & $2.67(1.97-3.62)$ & $<0.001$ \\
\hline
\end{tabular}


Table 4. Cox Regression for the association between frailty and all-cause mortality, all stroke and any bleeding

\begin{tabular}{|c|c|c|c|c|c|c|c|c|}
\hline Level of frailty & $\begin{array}{l}\text { Events/no. at } \\
\text { risk }\end{array}$ & Person-years & $\begin{array}{l}\text { Incidence rate } \\
\text { per } 100 \text { person- } \\
\text { years }\end{array}$ & $\begin{array}{l}\text { Population } \\
\text { attributable } \\
\text { risk }\end{array}$ & $\begin{array}{l}\text { HR (95\% CI) } \\
\text { unadjusted }\end{array}$ & $\mathrm{p}$-value & $\begin{array}{l}\text { HR }(95 \% \mathrm{CI}) \\
\text { adjusted }\end{array}$ & $\mathrm{p}$-value \\
\hline & \multicolumn{8}{|c|}{ All-cause mortality } \\
\hline non- frail & $8 / 681$ & 1463 & 0.6 & & Ref. & & Ref. & \\
\hline pre- frail & $95 / 1436$ & 2931 & 3.2 & 0.48 & $5.98(2.91-12.31)$ & $<0.001$ & $5.07(2.43-10.59)$ & $<0.001$ \\
\hline \multirow[t]{2}{*}{ frail } & $56 / 252$ & 484 & 11.6 & 0.33 & $21.51(10.25-45.14)$ & $<0.001$ & $16.72(7.75-36.05)$ & $<0.001$ \\
\hline & \multicolumn{8}{|l|}{ Stroke } \\
\hline non- frail & 10 / 681 & 1447 & 0.7 & & Ref. & & Ref. & \\
\hline pre- frail & $29 / 1436$ & 2904 & 1.0 & 0.17 & $1.47(0.72-3.02)$ & 0.3 & $1.43(0.67-3.06)$ & 0.35 \\
\hline \multirow[t]{2}{*}{ frail } & $11 / 252$ & 476 & 2.3 & 0.15 & $3.48(1.48-8.20)$ & 0.004 & $3.29(1.29-8.39)$ & 0.01 \\
\hline & \multicolumn{8}{|l|}{ Bleeding } \\
\hline non- frail & 52 / 681 & 1389 & 3.7 & & Ref. & & Ref. & \\
\hline pre- frail & 175 / 1436 & 2730 & 6.4 & 0.22 & $1.71(1.26-2.34)$ & $<0.001$ & $1.53(1.11-2.13)$ & 0.01 \\
\hline frail & 46 / 252 & 438 & 10.5 & 0.10 & $2.82(1.90-4.20)$ & $<0.001$ & $2.46(1.61-3.77)$ & $<0.001$ \\
\hline
\end{tabular}

Data are presented as Hazard ratio (HR) with 95\% confidence intervals (CI), reference value is non- frail (frailty index $\leq 0.1$ )

Model adjusted for age, sex, type of oral anticoagulation, any antiplatelet therapy, type of atrial fibrillation, education, smoking 
Figure 1. Cumulative incidence of unplanned hospitalizations (a), all-cause mortality (b), any bleeding (c) and all stroke (d) stratified by levels of frailty.
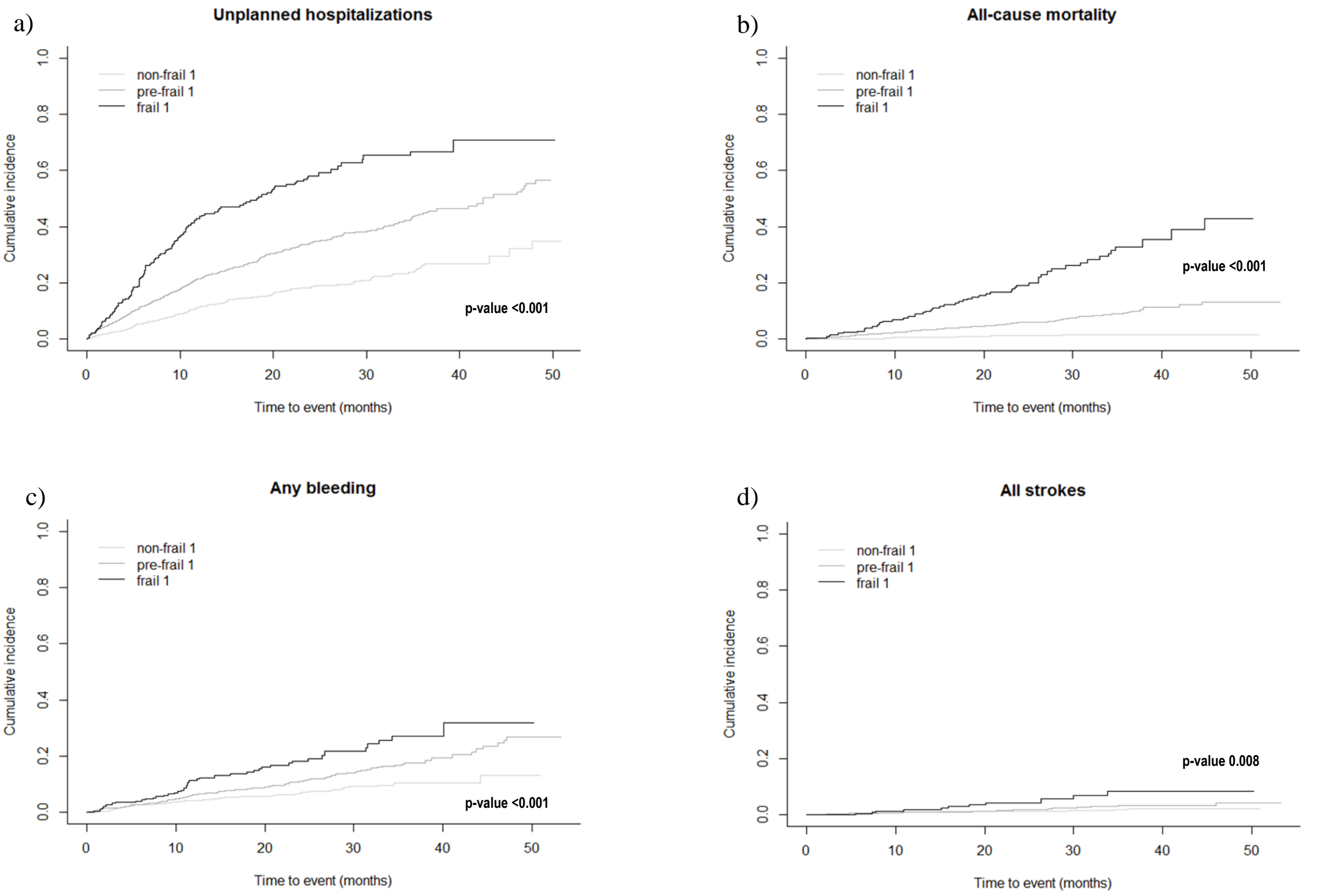
Figure 2. Receiver Operating Characteristic (ROC) curve of age and sex adjusted frailty index and $\mathrm{CHA}_{2} \mathrm{DS}_{2}$-VASc score for stroke

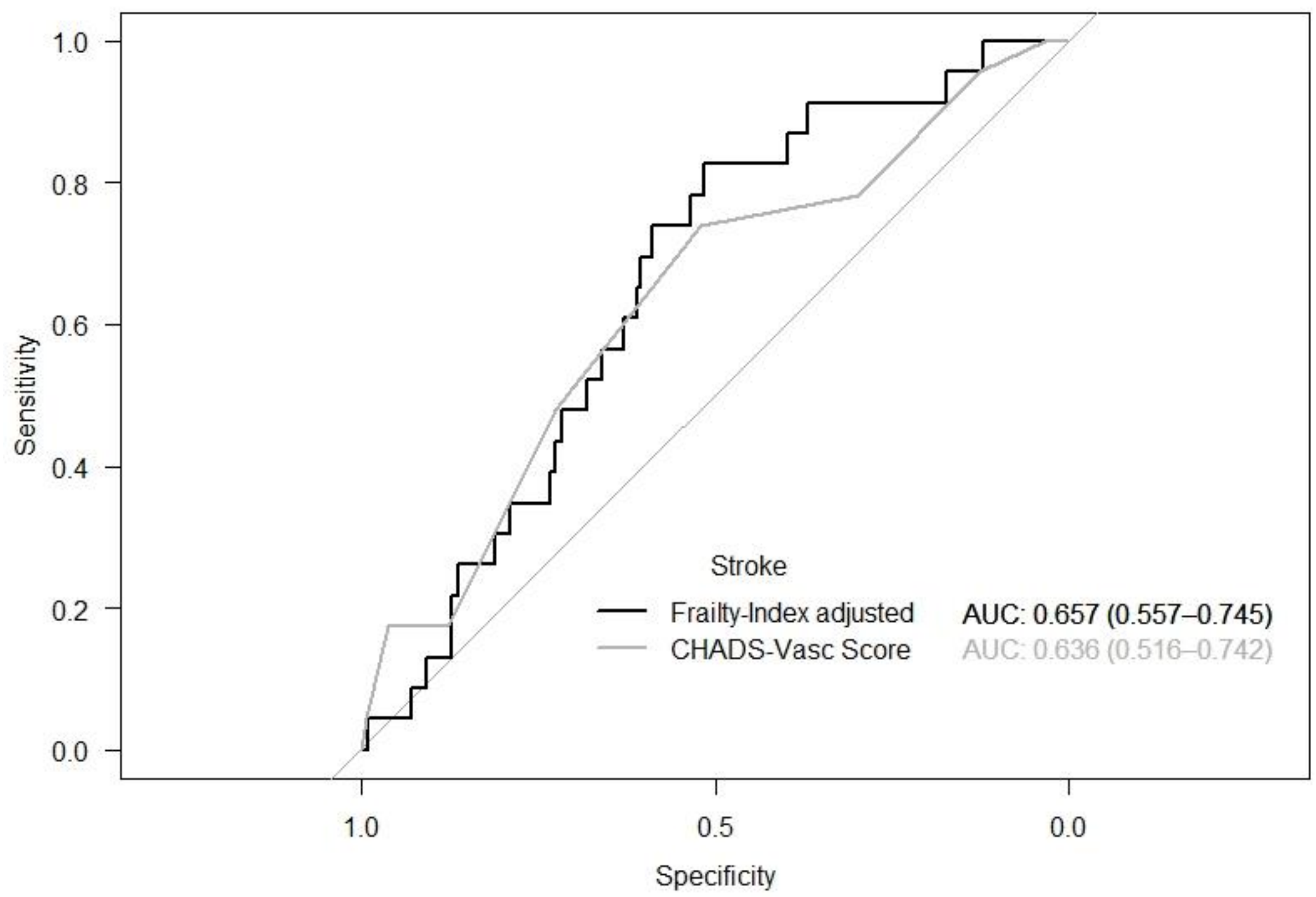


Take home figure. Prevalence and impact of frailty in patients with AF
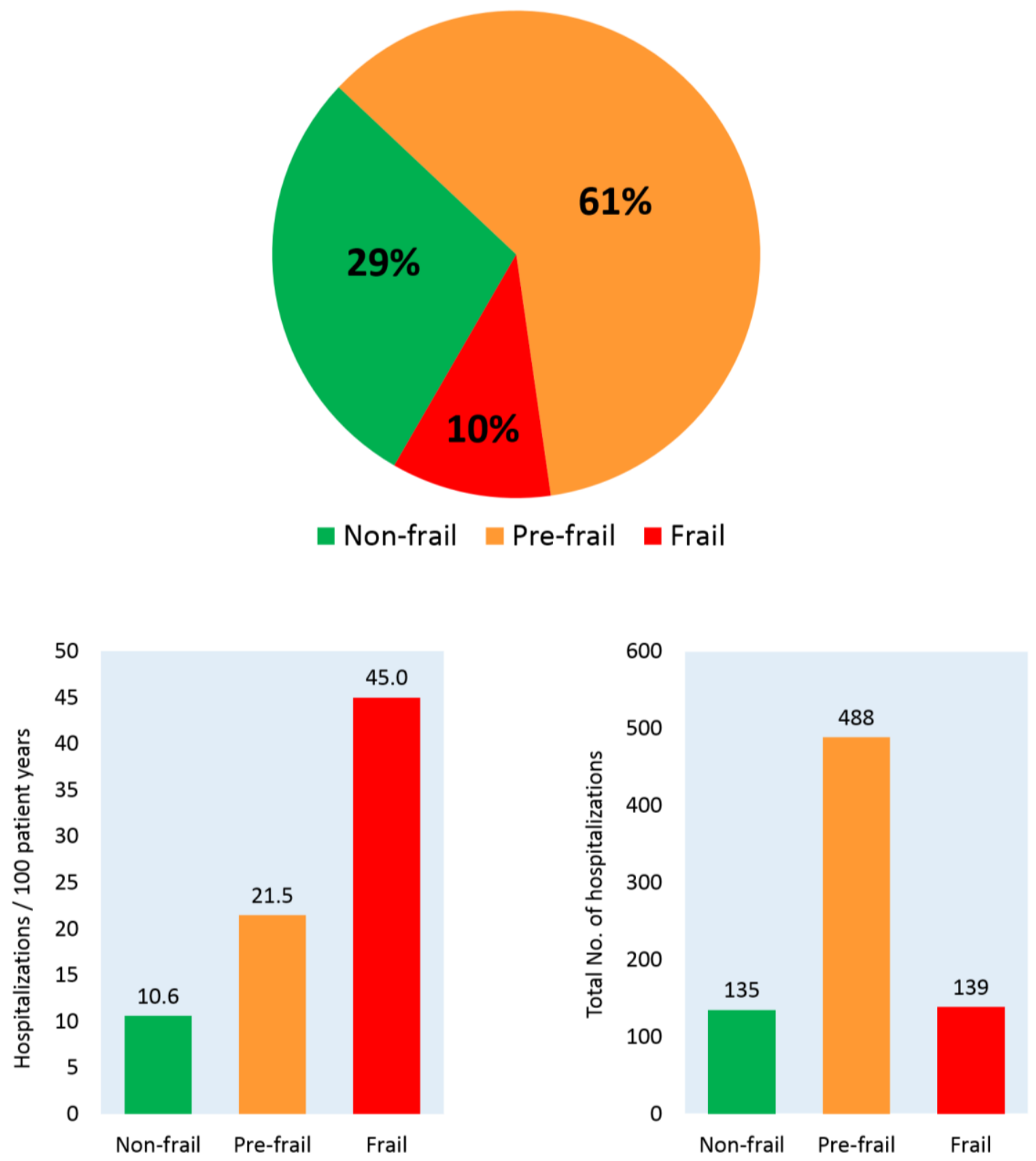